\title{
Abstract
}

\section{Dynamic Programming Model Estimates of Social Security Disability Insurance Application Timing}

\author{
Richard V. Burkhauser, J. S. Butler, and Gulcin Gumus
}

This paper develops a dynamic programming model of the Social Security Disability Insurance (SSDI) application timing decision. We estimate the time to application from the point at which a health condition first begins to affect the kind or amount of work that a currently employed person can do. We use Health and Retirement Study (HRS) and restricted access Social Security earnings data for estimation. Our results show that the type of worklimiting health condition, presence of employer accommodation, and the relative value of income in the application state to income in the work state significantly affect the timing of SSDI application.

Published in:

Journal of Applied Econometrics, Volume 19, Issue 6, 2004, Pages 671-685 For full text see publisher's website at: http://www.johnwiley.com.au/home.htm 